\title{
Pembentukan Keluarga Shaleh Dalam Komunikasi Islam: Studi Komparasi Penafsiran Al-Qur'an
}

\section{(Islamic Communication Model in Forming Pious Families: Comparative Study Of The Interpretation Of The Qur'an)}

\author{
Muhammad Roni ${ }^{1 \bowtie}$, M. Anzaikhan ${ }^{2}$, Arafit Hasan ${ }^{3}$ \\ ${ }^{1}$ Program Studi Komunikasi dan Penyiaran Islam, Institut Agama Islam Negeri Langsa, Indonesia \\ 2 Program Studi Komunikasi dan Penyiaran Islam, Institut Agama Islam Negeri Langsa, Indonesia \\ ${ }^{3}$ Program Studi Komunikasi dan Penyiaran Islam, Institut Agama Islam Negeri Langsa, Indonesia

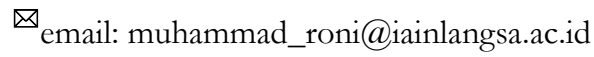

\begin{tabular}{ccc}
\hline First received: & Revised: & Final Accepted: \\
15 May 2021 & 7 June 2021 & 21 June 2021 \\
\hline
\end{tabular}

\begin{abstract}
The formation of a pious family should not only start when in the womb phase, more than that, Islam and its teachings have led its followers to start forming a pious family from the methods and criteria for choosing the right life partner. Choosing a life partner and educating children all desperately need ideal communication as recommended in the Qur'an. The research method that the writer will use is the comparative analysis of the text against the interpretations (tafsir) of the Qur'an. The data collection technique for this research is library study by examining materials from theories related to the problems discussed based on related books and can support the author's research.The primary data source is the verses of the Qur'an, selected several verses about the pious family and communication in Islam. As a result, the word "shaleh" or "pious" is found 143 times in the Qur'an, while the word "family" is found 67 times. After doing the research, it can be concluded that Allah has informed in the Qur'an that forming a pious family is very much influenced by communication factors in both individual and group life.
\end{abstract}

Keywords : Family; Pious; Communication.

\begin{abstract}
ABSTRAK
Pembentukan keluarga shaleh seharusnya bukan hanya dimulai ketika dalam masa kandungan, lebih dari itu Islam melalui sumber ajarannya menuntun umatnya untuk memulai membentuk keluarga shaleh dimulai dari cara dan kriteria memilih pasangan hidup yang tepat. Memilih pasangan hidup dan mendidik anak semuanya membutuhkan komunikasi yang ideal sebagaimana yang dianjurkan dalam AlQuran. Metode penelitian yang akan penulis gunakan adalah komparasi analisis teks terhadap tafsir-tafsir Al-Quran. Teknik pengumpulan data bagi penelitian ini adalah studi perpustakaan yaitu dengan menelaah bahan-bahan dari teori-teori yang berhubungan dengan permasalahan yang dibahas berdasarkan buku-buku yang berhubungan serta dapat mendukung atau menyokong penelitian penulis. Sumber data primer adalah ayat-ayat Al-Quran yang dipilih beberapa ayat-ayat tentang keluarga shaleh dan komunikasi dalam Islam. Hasilnya, ditemukan Kata 'shaleh' atau 'saleh' sebanyak 143 kali dalam Al-Quran, sedangkan kata 'keluarga' ditemukan 67 kali. Setelah dilakukan penelitian maka dapat disimpulkan bahwa Allah menginformasikan dalam Al-Quran dalam membentuk keluarga shaleh sangat dipengaruhi oleh faktor komunikasi baik dalam hidup berindividu maupun kelompok.
\end{abstract}

Kata kunci : Keluarga; Shaleh; Komunikasi.

\section{PENDAHULUAN}

Al-Qur'an membimbing manusia kepada kebahagiaan. Ia mengajarkan kepercayaan yang sejati, akhlak yang mulia dan perbuatan-perbuatan benar yang menjadi dasar kebahagiaan individu dan kelompok umat manusia (Yusmar, 2017). Dalam Al-Qur'an, ditegaskan pula ketentuan 
yang berkaitan dengan kehidupan antara suami dan istri dalam keluarga yang menjadi elemen dalam komunikasi serta membentuk keluarga yang shaleh.

Gagalnya terbentuk anak shaleh bukan hanya disebabkan anak, perhatian orangtua juga sangat menentukan. Kurangnya perhatian dan waktu orangtua dapat menyebabkan anak menyimpang, khususnya terhadap kelangsungan proses pendidikan dalam keluarga. Dalam berbagai kasus kegagalan pendidikan anak banyak disebabkan karena tidak adanya kedamaian dan ketenteraman dalam keluarga sebagai akibat dari tidak adanya perhatian terhadap anak(Wismanto, 2014).

Urgensi pembentukan keluarga sangat dipengaruhi aspek komunikasi orangtua dan anaknya. Hubungan akrab antara orang tua dan anak sangat penting untuk dibina dalam keluarga. Keakraban hubungan itu dapat dilihat dari frekuensi pertemuan antara orang tua dan anak dalam suatu waktu dan kesempatan. Untuk menjalin hubungan yang akrab dalam keluarga tidak mesti harus diawali dengan pertemuan formal. Pertemuan informal juga memiliki nilai strategis dalam mengakrabkan hubungan orang tua dengan anak(Wismanto, 2014).

Terkadang via pertemuan informal pesan-pesan kebaikan dapat tersalurkan secara efektif. Ketika anak-anak duduk bersama antarsesama mereka, orang tua harus pandai memanfaatkan moment tersebut untuk duduk bersama mereka, memahami mereka, bermain bersama mereka, berbicara dan berdialog yang disesuaikan dengan tingkat berpikir dan dunia anak-anak(Chairani et al., 2009) seebab Pembentukan karakter dan mental anak sangat dipengaruhi oleh kesiapan orangtua dalam mendidik, membina, mengontrol bahkan bekerjasama dengan setiap elemen yang melibatkan anak.

Dalam membentuk dan membina keluarga yang shaleh tentu harus dimulai sejak dini. Hal tersebut tak terlepas dari peran orangtua dalam mendidik anak agar menjadi sosok yang shaleh dan shaleha. Ada beberapa faktor penting dalam mendidik anak sebagaimana yang AlQuran anjurkan, seperti kasih sayang serta memanggilnya dengan nama yang baik sebagaimana kisah nabi Lukman (A. Nurdin, 2021). Memberikan keteladanan seperti berkata jujur walau hal sepele, dan berikhtiar semaksimal mungkin agar diberikan anak yang shaleh.

Faktor di atas, merupakan syarat minimal yang harus diimplementasikan agar anak yang shaleh dapat terwujud. Disamping itu, karakter orangtua dalam mendidik anak juga harus mendukung satu sama lain. Jika muatan pendidikannya sudah bagus namun metode penerapannya keliru maka justru akan mengakibatkan anak menjadi pembangkang dan tidak menghormati orangtuanya. Adapun beberapa sikap orangtua yang menyebabkan anak tidak menghormatinya adalah; komunikasi yang buruk, sikap otoriter orangtua, orangtua yang selalu mengkeritik, tidak paham keinginan anak, terlalu memanjakan anak, memberi contoh yang buruk, tidak meluangkan waktu yang cukup, dan masih banyak lagi (Huda, 2017).

Fenomena tersebut tentu berbeda denga cara Nabi Ibrahim dalam mendidik anaknya. Nabi Ibrahim mempunyai sifat edukasi penanaman aqidah yang benar kepada jiwa keluarga. Selain itu, ketauladanan yang dapat dipetik dari kisah Nabi Ibrahim yakni komunikasi yang interaktif terhadap istri dan anak. Karakter Nabi Ibrahim yang berjiwa pendidik tinggi mampu menitipkan hakikat kebenaran melalui lisannya sehingga diterima oleh istri dan anaknya dengan penuh keridhaan (Ilyas, 2018).

\section{METODE PENELITIAN}

Penelitian ini menggunakan metode content analysis atau analisis isi, yaitu analisis ilmiah tentang isi pesan suatu komunikasi. Teknik content analysis (analisis isi) adalah teknik penelitian untuk membuat inferensi-inferensi (proses penarikan kesimpulan berdasarkan pertimbangan yang dibuat sebelumnya atau pertimbangan umum) yang dapat ditiru (replicable) dan shahih (kebenaran) data dengan perhatian konteksnya. Content Analysis (analisis) adalah metode penelitian yang bersifat pembahasan terhadap isi suatu informasi tertulis (Nana \& Elin, 2018). 
Dalam penelitian ini penulis menggunakan metode content analisis sebagai metode untuk menganilisis isi dari pembahasan penelitian yang dikutip dari tafsir modern seperti Jalaluddin As- Sayuthi, terj. Tim Abdul Hayyie (Sebab Turunnya Al-Quran). Jalaluddin Abdurohman As-syuyuthi, terj. Rohadi Abu Bakar (Asbabun Nuzul, sebab Turunnya AyatAyat Al-quran). Qamaruddin Shaleh (Asbababun Nuzul, Latar Belakang Historis Turunnya Ayat-Ayat Al-Quran). M. Quraish Shihab (Tafsir Al- Misbah Pesan, Kesan dan keserasian AlQuran.

Peneliti menggunakan pendekatan kualitatif karena permasalahan yang dibahas dalam penelitian ini tidak berkenaan dengan angka-angka, tetapi mendeskripsikan, menguraikan, dan menggambarkan tentang konsep hidup sederhana menurut Al-Quran berdasarkan kajian tafsir.

\section{HASIL PENELITIAN DAN PEMBAHASAN}

Hasil penelitian menunjukkan bahwa komunikasi adalah media penting dalam membentuk keluarga shaleh. Pada Al-Qur'an terdapat banyak indikasi terkait ayat tersebut, diantaranya; berkata benar, berkata baik, berkata yang mudah dipahami, berkata pantas, perkataan yang mulia, perkataan yang ringan, perkataan yang lembut, dan memanggil dengan nama yang baik.

Berkata benar, terdapat pada surat al-Ahzab: 70 yang artinya; "Hai orang-orang yang beriman, bertakwalah kamu kepada Allah dan Katakanlah Perkataan yang benar." Ayat ini mengintruksikan bahwa syarat dari takwa adalah berkata yang benar. Bila dikaitkan dengan keluarga, syarat agar terbentuk keluarga shaleh adalah kejujuran. Antara suami dan istri harus saling jujur, begitu juga terhadap anak-anak dan elemen lainnya.

Berkata baik, Pada surat An-nisa: 8 artinya; "Dan apabila sewaktu pembagian itu badir kerabat, anak yatim dan orang miskin, Maka berilah mereka dari harta itu (sekedarnya) dan ucapkanlah kepada mereka Perkataan yang baik." Ayat ini langsung mengarah pada dimensi komunikasi dan dimensi keluarga secara langsung. Perkataan yang baik adalah sebuah contoh dan model berfikir bagi kerabat dan anak-anak.

Berkata yang mudah dipahami, terdapat pada Surat An-Nisa: 63 yang artinya; "Mereka itu adalah orang-orang yang Allah mengetahui apa yang di dalam hati mereka. karena itu berpalinglah kamu dari mereka, dan berilah mereka pelajaran, dan Katakanlab kepada mereka Perkataan yang berbekas pada jiwa mereka". Makna kata berbekas disini memiliki makna mudah dipahami atau dimengerti. Dalam membina keluarga shaleh, harus ada komunikasi yang jelas dan mudah dimengerti satu sama lain. Apabila komunikasi antara ayah dan anak tidak terkoneksi dengan baik maka yang terjadi adalah pembangkangan anak. Fenomena saat ini, anak benci dan kecewa dengan orangtua salah satunya karena tidak paham atas kebaikan yang diinginkan ayahnya.

Berkata yang mulia, terdapat pada Surat al-Isra ayat 23 yang artinya; Dan Tubanmu telah memerintabkan supaya kamu jangan menyembah selain Dia dan hendaklah kamu berbuat baik pada ibu bapakmu dengan sebaik-baiknya. jika salah seorang di antara keduanya atau Kedua-duanya sampai berumur lanjut dalam pemeliharaanmu, Maka sekali-kali janganlah kamu mengatakan kepada keduanya Perkataan "ah" dan janganlah kamu membentak mereka dan ucapkanlah kepada mereka Perkataan yang mulia." Selain tentang komunikasi berupa perkataan yang mulia, ayat ini juga sangat jelas mengarah kepada pembentukan keluarga shaleh. Hal tersebut tercermin dari perintah Allah Swt terhadap manusia yang diminta berkata mulia pada ibu selaku orangtua nya.

Berkata lembut, terdapat pada Surat Thaha ayat 44 yang artinya; "Maka berbicaralah kamu berdua kepadanya dengan kata-kata yang lemah lembut, Mudah-mudahan ia ingat atau takut." Ini juga bagian dari komunikasi penting dalam membentuk keluarga shaleh. Seorang anak diminta berkata-kata lembut dengan orangtuanya meskipun mereka kafir sekalipun. Ini menunjukkan bahwa nasehat yang paling ideal adalah yang disampaikan dengan lemah lembut karena tidak membuat amarah menutupi fikiran keduanya.

Ucapan yang pantas, terdapat pada Surat Al-Isra ayat 28 yang artinya; "Dan jika kamu berpaling dari mereka untuk memperoleh rahmat dari Tubanmu yang kamu harapkan, Maka Katakanlah 
kepada mereka Ucapan yang pantas." Ucapan yang pantas adalah bagian dari kecerdasan berkomunikasi. Membina keluarga yang sholeh tidak akan terjadi apabila setiap elemen tidak pandai memposisikan dirinya dan orang lain dalam berbicara. Sebagai contoh, orang yang lebih tua harus dipanggil kakak atau abang, begitu juga saat memanggil orang yang seudia dengan ayah atau ibu, baiknya disebut dengan sebutan yang pantas seperti bapak, ibu, paman, dan sejenisnya.

\section{Upaya Pembentukan Keluarga Shaleh}

Pembentukan keluarga shaleh dapat dilakukan dalam beberapa cara, pertama, pemilihan calon pasangan (suami/istri) yang tepat dan sesuai dalam pandangan agama. Islam menjelaskan bahwa ada 4 kriteria dalam memilih pasangan yang baik yaitu; karena ketakwaannya, karena kecantikan/ ketampanannya, karena hartanya dan karena keturunannya (Najwah, 2018). Hal tersebut bukan tanpa alasan, sifat manusia secara disadari atau tidak akan condong lebih menyukai sesuati yang memiliki daya tarik lebih seperti paras, harta, jabatan dan lai-lain.

Kedua, selalu berdoa untuk mendapatkan keluarga yang shaleh. Pasangan dan keturunan adalah anugerah dari Allah. Karena itu, saat akan memilih pasangan kita dianjurkan untuk banyak berdoa agar diberikan petunjuk dalam memilih pasangan yang baik sehingga kelak mampu menjadi orangtua dan panutan yang baik pula bagi anak-anak. Berikut doa agar diberikan pasangan dan keturunan yang saleh sebagaimana dikatakan dalam Al-Quran;

"Ya Tuban kami, anugerabkanlah kepada kami isteri-isteri kami dan keturunan kami sebagai penyenang hati (kami), dan jadikanlah kami imam bagi orang-orang yang bertakwa." (Q.S. AlFurqan; 74)

"Ya Tubanku, anugerabkanlah kepadaku (seorang anak) yang termasuk orang-orang yang saleh. Maka Kami beri dia khabar gembira dengan seorang anak yang amat sabar.” (QS. al-Shaffat: 100101)

Ketiga, peran suami saat istri sedang hamil. Diawali sejak usia dini. Hendaknya sejak anak masih berada di dalam kandungan, ibunya harus selalu mengkonsumsi makanan yang halal. Jangan sekali-kali memakan dan meminum sesuatu yang syubhat atau bahkan haram. Nabi Muhammad bersabda: "Setiap daging yang tumbuh dari sesuatu yang haram, neraka lebih berhak baginya" (Azmi \& Hoesni, 2019). Jadi suami harus menafkahi istrinya dengan jalan yang baik dan benar agai menjadi berkah bagi kesehatan dan keturunannya kelak.

Keempat, mendidik keluarga agar menjadi keluarga yang shaleh. Seorang kepala keluarga harus mendidik dan mengajarkan istri dan anaknya untuk mengenal Allah, dimengertikan tentang tata cara beribadah, halal-haram, hal-hal yang menyebabkan kemurtadan, dan lain-lain. Setelah itu anak diberikan pendidikan yang membentuk karakternya sebagai sosok individu berahklak mulia (Azmi \& Hoesni, 2019). Jika seorang ayah tidak mampu atau tidak memiliki kapasitas dalam mendidik, maka Ia harus mencarikan guru untuk mendidik anak dan istrinya agar memperoleh ilmu yang bermanfaat untuk kemaslahatan dunia dan akhirat.

\section{Membentuk Keluarga Shaleh dengan Dukungan Qurani}

Asas yang paling penting dalam pembentukan sebuah keluarga Qurani ialah rumah tangga yang dibina atas landasan taqwa, berpandukan Al-Quran dan Sunnah dan bukannya atas dasar cinta semata-mata. Ia menjadi panduan kepada suami istri sekiranya menghadapi perbagai masalah yang akan timbul dalam kehidupan berumahtangga (Thohir, 2015). Seorang muslim yang benar adalah mereka yang menjadikan Al-Quran sebagai imamnya bukan sebaliknya. Sehingga apa yang dianjurkan dalam Al-Quran termasuk bila mengalami permasalahan dalam keluarga maka akan mengembalikannya pada ketentuan yang digariskan Al-Quran: 
"Hai orang-orang yang beriman, taatilah Allah dan taatilah Rasul (Nya), dan ulil amri di antara kamu. Kemudian jika kamu berlainan pendapat tentang sesuatu, maka kembalikanlah ia kepada Allah (Al Quran) dan Rasul (sunnabnya), jika kamu benar-benar beriman kepada Allah dan hari kemudian. Yang demikian itu lebih utama (bagimu) dan lebih baik akibatnya."(QS. An-Nisa: 59).

Rumah tangga tanpa kasih sayang tentu bukanlah sebuah harapan siapapun. Tanpa 'almawaddah' dan 'al-Rahmab', masyarakat tidak akan dapat hidup dengan tenang dan aman terutamanya dalam institusi kekeluargaan. Dua perkara ini sangat-sangat diperlukan kerana sifat kasih sayang yang wujud dalam sebuah rumah tangga dapat melahirkan sebuah masyarakat yang bahagia, saling menghormati, saling mempercayai dan tolong-menolong (Thohir, 2015). Pada dasarnya melakukan peraturan rumah tangga merupakan perekat keluarga. Akan tercipta hubungan hak-hak dan kewajiban antara anggota keluarga.

Selanjutnya Kedua orang tua sebagai poros keluarga mendapat perhatian dan perlakuan khusus dalam Islam. Al-Quran setelah memberi perintah menyembah Allah dan larangan menyekutukan-Nya, juga memerintahkan untuk berbuat baik kepada kedua orang tua. Dalam surat An-Nisaa' ayat 36, Allah berfirman:

"Sembablah Allah dan janganlah kamu mempersekutukan-Nya dengan sesuatupun. Dan berbuat baiklah kepada kedua orang tua." Sembablah Allab dan janganlah kamu mempersekutukan-Nya dengan sesuatupun. Dan berbuat baiklah kepada dua orang ibu-bapa, karib-kerabat, anak-anak yatim, orang-orang miskin, tetangga yang dekat dan tetangga yang jauh, dan teman sejawat, ibnu sabil dan bamba sabayamu. Sesunggubnya Allab tidak menyukai orang-orang yang sombong dan membangga-banggakan diri.” (QS. An-Nisa: 36).

Selain ayat di atas, banyak dalam Al-Quran yang menyeru agar berbuat baik kepada orang tua. Surat Al-An'am ayat 151 menyebutkan, "Janganlah kamu mempersekutukan sesuatu dengan Dia dan berbuat baiklah kepada kedua orang tua." Sementara surat Al-Israa' menyatakan, "Dan Tuhanmu telah memerintahkan supaya kamu jangan menyembah selain Dia dan hendaklah kamu berbuat baik pada ibu bapakmu dengan sebaik-baiknya. Jika salah seorang di antara keduanya atau kedua-duanya sampai berusia lanjut dalam pemeliharaanmu, maka sekali-kali janganlah kamu mengatakan kepada keduanya perkataan "ah" dan janganlah kamu membentak mereka dan ucapkanlah kepada mereka perkataan yang mulia."

Ini menunjukkan bahwa komunikasi sangat berperan penting dalam membentuk kepribadian qurani. Secara tegas Al-Quran menginformasikan bahwa seorang anak dilarang mengucapkan perkataan 'ah' yang mana bisa dikatagorikan kedalam bentuk komunikasi yang buruk.

\section{Ayat-ayat Al-Quran Tentang Komunikasi dan Keluarga Shaleh}

a. Term-Term Kekuarga Shaleh dalam Al-Quran

\begin{tabular}{|c|l|l|c|}
\hline No & $\begin{array}{c}\text { Lafadz } \\
\text { Terkait } \\
\text { Shaleh }\end{array}$ & Nama Surat & $\begin{array}{c}\text { Jumlah } \\
\text { Ayat }\end{array}$ \\
\hline 1 & $\begin{array}{l}\text { Anak yang } \\
\text { Shaleh }\end{array}$ & Ali Imran: 35, 39; Al-Araf: 189 & 3 \\
\hline 2 & $\begin{array}{l}\text { Wanita yang } \\
\text { Shaleh }\end{array}$ & An-Nisa: 34 & 1 \\
\hline 3 & Amal-amalan & Ali Imran: 57; An-Nisa`ayat 57, 122, 124, 173; & 85 \\
\hline
\end{tabular}




\begin{tabular}{|c|c|c|c|}
\hline & yang shaleh & $\begin{array}{l}\text { Al-Araf: 42; Al-Anam: 127; Al-Isra: 9; Al-Kaft: 2, } \\
\text { 30, 46, 107, 110; At-Taubah: 120, 121; Almaidah: } \\
\text { 9, 93; Yunus: 4, 9, 11; Hud: 11, 23; Ar-Raad: 29; } \\
\text { Ibrahim: 23; An-Nahl: 97; Maryam: 60, 76, 96; } \\
\text { At Taha: 75, 82, 112; Al-Anbiya: 94; Al-Hajj: 14, } \\
\text { 23, 50, 56; Almukninun: 51, 100; An-Nur: 55; Al- } \\
\text { Furqan: 70, 71; Asy-Syuara: 22, 23, 26, 227; Al- } \\
\text { Qasas: 67, 80; Al-Angkabut: 7, 9, 58; Ar-Rum: } \\
\text { 15, 44, 45; Lukman: 8; As-Sajadah: 12, 19; Al- } \\
\text { Ahzab: 31; As-Saba: 4, 11, 37; Al-Fatir: 7, 10, 37; } \\
\text { Shaad: 24, 28; Al-Mukmin: 40, 58; Fussilat: 8, 33, } \\
\text { 46; Al-Jasiah: 15, 21, 30; Al-Ahqaf: 15; } \\
\text { Muhammad: 2, 12; Al-Fath: 29; At-Tagabun: 9; } \\
\text { At-Talaq: 11; Al-Insyiqaq: 25; Al-Buruj: 11; Al- } \\
\text { Fajr: 24; At-Tin: 6; Al-Bayinah: 7; Al-Asr: 3 }\end{array}$ & \\
\hline 4 & $\begin{array}{l}\text { Orang-orang } \\
\text { yang shaleh }\end{array}$ & $\begin{array}{l}\text { Al-Baqarah: 130; Ali Imran: 46, 114; Almaidah: } \\
\text { 69, 84; An-Nisa: 69; Al-An`am: 19, 55, 85; At- } \\
\text { Thamrin: 11; Al-Qalam: 50; Al-Jinn: 11; As- } \\
\text { Safaat: 100, 112; Al-Mukmin: 8; Al-Munafiqun: } \\
\text { 10; Al-Araf: 168, 196; At-Taubah: 75; Yusuf: } \\
\text { 101; Ar-Raad: 23; An-Nahl: 122; Al-Kaft: 82; Al- } \\
\text { Anbiya: 72, 75, 86, 105; Asy-Syuara: 83; Al- } \\
\text { Angkabut: } 27\end{array}$ & 29 \\
\hline 5 & Nabi Shaleh & $\begin{array}{l}\text { Al-A'raf : 73, 75, 77, 79; Hud: 61, 62, 63, 65, 66, } \\
\text { 89; Asy-Syuara: 142, 155; An-naml: 45, 47; Asy- } \\
\text { Syam: } 13\end{array}$ & 14 \\
\hline
\end{tabular}

b. Term-Term Komunikasi dalam Al-Quran

\begin{tabular}{|c|l|l|c|}
\hline No & \multicolumn{1}{|c|}{$\begin{array}{c}\text { Lafadz Terkait } \\
\text { Komunikasi }\end{array}$} & $\begin{array}{c}\text { Nama Surat } \\
\text { Ayat }\end{array}$ \\
\hline 1 & Qaulan makrufan & $\begin{array}{l}\text { Al-Baqarah: 235; An-Nisa: 5 dan 8; Al- } \\
\text { Ahzab: 32 }\end{array}$ & 3 \\
\hline 2 & Qaulan Sadidan & An-Nisa: 9; Al-Ahzab: 70 & 2 \\
\hline 3 & Qaulan balighan & An-Nisa: 63 & 1 \\
\hline 4 & Qaulan Kariman & Al-Isra: 23 & 1 \\
\hline 5 & Qaulan Maysuran & Al-Isra: 28 & 1 \\
\hline 6 & Qaulan layyinan & At-Thaha: 44 & 1 \\
\hline
\end{tabular}

\section{Konsep Keluarga Shaleh dalam Al-Quran}

Orang yang shaleh dalam Al-Quran sangat banyak sekali, baik umat yang terdahulu ataupun para Nabi, dengan tujuan bagi umat Islam dan menjadi umat untuk menegakkan agama Allah 
di permukaan bumi ini, adalah agama Islam. Konsep keluarga ssaleh dalam Al-Quran adalah:

1. Patuh kepada perintah Allah dan menjauhi segala larangannya. Orang Islam adalah orang yang telah menjalankan perintah Allah dan menjauhi semua larangan-Nya. Siapa saja yang telah menjalankan perintah Allah, Ia telah mengamalkan Islam (Muslim). Namun, apabila belum beramal shaleh secara istiqomah, maka Ia belum mencapai derajat ihsan (keutamaan) (Zubaedy, 2019).

2. Berbakti kepada kedua orang tuanya. Anak-anak secara khususnya memang sangat memerlukan arahan untuk berbakti kepada kedua orang tua, Generasi yang mendidik dan merawatnya. Karena, biasanya Keberadaan, Perasaan, dan Perhatian anak-anak itu di arahkan untuk generasi yang akan menggantikan mereka, bukan yang akan mereka gantikan. Sementara mereka didorong untuk menyongsong kehidupan masa depan yang akan datang dari Allah yang maha pengasih lagi maha penyayang yang tidak mengabaikan orangtua dan anak, yang tidak melupakan anak-anak dan orang tua, dan mengajarkan hamba-hamba-Nya untuk saling menyayangi baik mereka sebagai anak maupun sebagai orang tua (Zubaedy, 2019).

3. Konsep keluarga shaleh harus memiliki sikap saling mendoakan antara tiap elemennya. Anak selalu mendoakan kepada kedua orangtuanya, begitu juga sebaliknya. Bentuk syukur kepada Allah adalah dengan cara melakukan shalat lima waktu sehari semalam serta menunaikan amalan lainnya, sedangkan syukur kepada orangtua atau anak adalah dengan cara mendoakannya lima waktu sehari semalam (Nursyamsu, 2017).

4. Menjaga kehormatan anggota keluarga. Keluarga adalah komponen kecil dari suatu bangsa. Bangsa yang baik tentu di bangun dari komponen- komponen yang baik pula. Setiap komponen tersebut tentunya mempunyai nilai dan kehormatan tersendiri. Kehormatan keluarga, terutama orang tuaharus dijaga oleh sang anak, baik dalam lingkungan keluarga maupun di luar lingkungan keluarga. Bahkan dalam pergaulan sehari-hari pun, tetap harus dijaga karena sangat mungkin si anak secara tidak sengaja malakukan penghina kepada orang tua sendiri (Ahmad Sudirman Abbas, 2008). Begitu juga sebaliknya, orangtua harus menjaga 'aib anaknya sendiri sebab baik-buruk anggota keluarga adalah beban dan tanggungjawab bersama.

5. Cinta dan sayang kepada fakir miskin, anak terlantar, anak yatim, dengan memberikan bantuan sesuai denagn keperluan mereka dan peduli serta tidak menjemu atau mengolokolok mereka sebab mereka adalah hamba Allah. Dengan memiliki sifat demikian maka keluarga akan senantiasa mengintropeksi diri dan menghargai kondisi keluarga orang lain.

6. Cinta kepada Al-Quran, dengan selalu membacanya, kemudian berusaha menghafalnya dan menjauhi apa yang dilarangnya. Cinta shalat lima waktu dengan tidak sekalipun meninggalkannya serta mengerjakan shalat-shalat sunah.

7. Berpegang teguh pada kebaikan. Tiadalah baginya kemaksiatan dan dosa-dosa besar, melainkan hanya dosa-dosa kecil setiap-tiap manusia tiadalah yang mampu untuk luput dari dosa kecil. Bahwasanya Ia senantiasa berpegang teguh pada kebaikan dan senantiasa menjauhi maksiat yang hanya mendekatkan dirinya pada murka Allah.

8. Murah hati dan rela berkorban untuk saudaranya. Hati yang mengasihi dan hati untuk melayani harus senentiasa kita miliki dalam menjalankan Amanat Agung-Nya, baik dalam lingkungan keluarga, studi, Pekerjaan, bisnis, bermasyarakat, maupun berbangsa dan Negara. Disaat kita dimampukan untuk mengerjakan hal tersebut dengan kerelaan hati dan ketaatan.

\section{Relevansi Ayat-ayat Al-Quran Tentang Pembentukan Keluarga Shaleh dalam Komunikasi Islam}

Relevansi menurut kamus Bahasa Indonesia berarti kaitan atau hubungan (Pusat Bahasa Departemen Pendidikan Nasional RI). Menurut Green, relevansi ialah sesuatu sifat yang 
terdapat pada dokumen yang dapat membantu pengarang dalam memecahkan kebutuhan akan informasi. Dokumen dinilai relevan bila dokumen tersebut mempunyai topik yang sama, atau berhubungan dengan subjek yang diteliti (topical relevance) (Suryani, 2012). Dalam penulisan ini, relevansi antara Al-Quran dan komunikasi Islam tentu sangat erat kaitannya, sebab Islam adalah ajaran yang bersumber dari Al-Quran dimana di dalamnya juga terdapat nilai-nilai yang menjelaskan tentang pembentukan keluarga shaleh. Terkait hal tersebut, Al-Quran yang berkaitan dengan pembentukan keluarga shaleh secara khusus pembagiannya disebutkan dalam surat Ali-Imran ayat 113 dan 114. Allah Berfirman;

"Mereka itu tidak sama; di antara Abli Kitab itu ada golongan yang berlaku lurus, mereka membaca ayat-ayat Allah pada beberapa waktu di malam hari, sedang mereka juga bersujud (sembahyang)." (QS. Ali-Imran: 113)

"Mereka beriman kepada Allah dan hari penghabisan, mereka menyurub kepada yang ma'ruf, dan mencegah dari yang munkar dan bersegera kepada (mengerjakan) berbagai kebajikan; mereka itu termasuk orang-orang yang saleh.” (QS. Ali-Imran: 114)

Dari dua ayat di atas, dapat diambil beberapa poin mengenai kriteria golongan keluarga yang shaleh diantaranya; membaca Al-Quran dimalam hari, mengerjakan qiyamun lail, menganjurkan berbuat baik, mencegah berbuat mungkar, dan bersegera dalam berbuat kebajikan. Pada prosesnya perlu ada yang mengkomunikasikan hal tersebut sehingga amanah Al-Quran sampai pada pendengar. Seperti halnya ayah yang mengajak anak dan istri untuk beramal shaleh dan berdakwah.

1. Membaca Al-Quran di waktu malam

Selain dalam teks Al-Quran, juga banyak hadis Nabi yang membicarakan tentang keutamakan dan keistimewaan membaca Al-Quran. Oleh karena itu, banyak diantara umatnya yang membacanya. Membacanya di waktu pagi dan sore bagi seorang muslim merupakan hal biasa. Akan tetapi membaca Al-Quran di waktu pertengahan malam adalah sesuatu hal yang luar biasa. Mengapa demikian? Karena firman allah dalam surat Ali-Imran ayat 113-114 mengelompokkan orang-orang yang membacanya di waktu pertengahan malam kedalam golongan orang-orang saleh.

Jadi, antara membaca Al-Quran di sepertiga malam ternyata memiliki relevansi dalam pembentukan keluarga shaleh. Dengan membiasakan diri beramal diwaktu malam sejatinya akan menempa pribadi ikhlas dan khusyuk dalam beribadah. Sedangkan relevansinya dengan komunikasi Islam terdapat pada penampaan diri terhadap rasa ikhlas dan sabar. Orang yang ikhlas dan sabar maka akan terbiasa berkomunikasi baik. Tidak mudah marah dan pedendam ketika bersosialisasi dengan orang lain.

2. Mengerjakan Qiyamul Lain

Bimbingan Islam dalam membentuk keluarga yang shaleh yang kedua berdasarkan AlQuran adalah anjuran menegakkan shalat malam atau tahajjud. Sejatinya shalat malam ini bisa dilakukan berbarengan dengan poin 1 diatas, yakni melakukannya sebelum membaca AlQuran.

3. Beriman kepada Allah

Selain membaca Al-Quran di pertengahan malam dan mengerjakan shalat tahajjud, juga memiliki relevansi yang lain yakni beriman kepada Allah, hari akhir dan beramal shaleh. Tanpa adanya iman tentu melaksanakan ibadah lainnya akan kehilangan esensi amalnya. Relevansinya dengan komunikasi Islam adalah bagaimana diri berkomunikasi dengan hati sendiri sehingga menanamkan nilai tauhid dalam beramal dan membentuk keluarga shaleh. Allah berfirman:

"Dan orang-orang yang beriman dan mengerjakan amal saleh benar-benar akan Kami masukean mereka ke dalam (golongan) orang-orang yang saleh.” (QS. Al-Angkabut: 9) 
4. Mengajurkan berbuat baik

Orang saleh bukan saja mengerjakan perbuatan baik untuk dirinya. Akan tetapi, ia juga harus mengajur orang lain berbuat kebaikan dan kesalehan sebagaimana ini juga didasarkan pada Al-Qquran surat Ali Imran ayat 114 di atas. Kaitannya dengan komunikasi Islam terlihat pada upaya Islam yang senantiasa menyeru umatnya berdakwah.

5. Mencegah kemunkaran.

Disamping sebagai pengajur dan penunjuk jalan kebaikan, pembentukan keluarga saleh juga bisa diimplementasikan dalam mencegah dirinya dan orang lain untuk berbuat kemungkaran. Hal ini juga didasarkan pada Alquran ali Imran ayat 114. Mencegah orang lain berbuat mungkar biasanya lebih mudah daripada mencegah dirinya padanya. Ibarat peribahasa mengatakan: "kuman diseberang lautan tanpak. Tapi gajah di pelupuk mata tak. Nampak." Oleh sebab itu, orang saleh dituntut harus memiliki ilmu pengetahuan agama yang mendalam. Bagaimana mungkin, ia bisa memberi saran dan nasehat kepada orang lain kalau dirinya itu bodoh, alias tidak berpengetahuan.

Hal ini senda dengan hadis nabi yang artinya; "Barang siapa melibat kemungkaran hendaknya merubah dengan tanganya (kekuasanya). Dan apabila masih tidak mampu juga, maka dengan hatinya. Yang demikian itu adalah selemah-lemahnya Iman.” (HR. Muslim). Relevansinya terhadap komunikasi Islam jelas terdapat pada poin kedua hadis di atas, dimana umat Islam diminta untuk mencegah kemungkaran (salah satunya) dengan lisan (komunikasi).

6. Bersegera dalam berbuat kebajikan

Ini adalah poin yang paling berat disbanding poin lainnya. Bersegara dalam berbuat kebajikan bukanlah suatu hal yang mudah. Coba kita perhatikan dalam kehidupan sehari-hari. Misalnya saja, mendengar suara adzan. Apakah langsung segera menyambut panggilan tersebut atau justru sebaliknya, bermalas-malas dan santai-santai saja? Orang yang langsung dengan segera menyambutnya bisa dikatagorikan orang shaleh. Bagi yang tidak, apalagi tidak ada alasan yang dimaklumi dalam Islam, maka mereka tergolong orang yang munafik. Hal ini didasarkan pada Al-Quran surat An-Nisa ayat 142;

"Sesunggubnya orang-orang munafik itu menipu Allah, dan Allah akan membalas tipuan mereka. Dan apabila mereka berdiri untuk shalat mereka berdiri dengan malas. Mereka bermaksud riya (dengan shalat) di hadapan manusia. Dan tidaklab mereka menyebut Allah kecuali sedikit sekali." (QS. An-Nisa: 142)

Adapun kaitannya dengan komunikasi Islam adalah bagaimana menyeimbangkan antara perkataan dan perbuatan. Seringkali ditemukan oknum yang berkomunikasi baik namun dalam praktiknya bertolak belakang. Dalam komunikasi Islam perkataan dan perbuatan harus sejalan sehingga disebut dengan istilah jujur.

\section{PENUTUP}

Dalam Al-Quran, istilah komunikasi paling intens disebutkan kepada manusia untuk berbicara atau berkata-kata baik. Baik itu berkata baik untuk orangtua, anak-istri, keluarga, maupun oranglain. Dalam Al-Qur'an, istilah shaleh paling sering ditemukan pada kata 'beramal shaleh' serta paling sering berdekatan dengan istilah 'orang yang beriman'. Hal tersebut mengindikasikan bahwa syarat dari amal atau keluarga shaleh terlebih dahulu harus didasari oleh keimanan (tauhid) yang benar. Tanpa ada iman maka defenisi shaleh tidak ada pula.

Komunikasi menjadi media penting dalam pembentukan keluarga shaleh. Hal tersebut dapat tercermin dari kisah Nabi Ibrahim yang termaktub dalam Al-Quran. Melalui komunikasi meskipun kabar buruk sekalipun maka seorang anak dan istri akan menerima dengan lapang dada dan pernuh keridhoan. Komunikasi merupakan indikator penting agar suatu perintah dalam Al-Quran dapat diterima oleh anggota keluarga. Meskipun kebenaran Al-Quran tidak 
terbantahkan, tanpa komunikasi yang baik maka anggota keluarga bisa berpaling dan menolaknya. Maka dari itu, Al-Quran senantiasa menganjurkan untuk berkata-kata baik dan mudah memaafkan guna terjalinnya komunikasi yang efektif.

Relevansi nilai-nilai Al-Quran terhadap komunikasi Islam terdapat dalam berbagai aspek seperti beriman dan beramal kepada Allah Swt dengan melakukan ibadah malam sebagai bentuk komunikasi terhadap sang khaliq. Melaksanakan dakwah untuk mengajak orang berbuat baik dengan komunikasi secara lisan. Mencegah perbuatan mungkar dengan perkataan dan bimbingan terhadap orang lain dan bersegera berbuat kebajikan sebagai bentuk kolerasi antara perkataan dan perbuatan.

\section{DAFTAR PUSTAKA}

Asy'ari, M. (2019). Metode, Sistem dan Prinsip Pembelajaran Bahasa Arab yang Inovatif. An Nabighoh: Jurnal Pendidikan Dan Pembelajaran Babasa Arab, 20(02), 288. https://doi.org/10.32332/an-nabighoh.v20i02.1465

Azmi, P. A. B. U., \& Hoesni, S. M. (2019). Gambaran Preferensi Pemilihan Pasangan Hidup Pada Mahasiswa Universiti Kebangsaan Malaysia. Journal of Chemical Information and Modeling, 13(2), 96-107.

Chairani, M., Wiendijarti, I., \& Novianti, D. (2009). Komunikasi interpersonal guru dan orang tua dalam mencegah kenakalan remaja pada siswa (studi deskriptif pada siswa kelas XI SMA Kolombo Sleman). Jurnal Ilmu Komunikasi, 7(2), 143-152.

Fitri, S. (n.d.). DAMPAK POSITIF D AN NEGATIF SOSIAL MEDIA.

Huda, M. (2017). Indikator Perilaku Konsumen Dalam Memenubi Kebutuban Primer. 3(2), 201-219.

Ilyas, M. (2018). Konsep Pendidikan Keluarga Dalam Al-Qur'an. Tawažn: Jurnal Pendidikan Islam, 11(1), 1. https://doi.org/10.32832/tawazun.v11i1.1623

Khair, A. (2016). ANALISIS KRITIS PEMIKIRAN WAHBAH AZ-ZUHAILI TENTANG PENETAPAN. 8(2), 143-158.

Malik, H. A. (2010). JURNAL DAKWAH DAN KOMUNIKASI DA' I SEBAGAI PEWARIS NABI Nabi-nabi Dipilib oleh Allab Nabi sebagai Pembawa Kabar Gembira dan Pemberi Peringatan. 4(2), 86-87.

Najwah, N. (2018). Kriteria Memilih Pasangan Hidup (Kajian Hermeneutika Hadis). Jurnal Studi Ilmu-Ilmu Al-Qur'an Dan Hadis, 17(1), 95. https://doi.org/10.14421/qh.2016.170105

Nana, D., \& Elin, H. (2018). Memilih Metode Penelitian Yang Tepat: Bagi Penelitian Bidang Ilmu Manajemen. Jurnal Ilmu Manajemen, 5(1), 288. https://jurnal.unigal.ac.id/index.php/ekonologi/article/view/1359

Nurdin, A. (2021). Modernization of Islamic Higher Education in Indonesia at A Glance: Barriers and Opportunities. International Journal of Multicultural and Multireligious Understanding, 8(3), 288. https://doi.org/10.18415/ijmmu.v8i3.2490

Nurdin, Z. (2017). Etika mencari pendamping hidup menurut islam. Syi'ar, 17(1).

Nursyamsu. (2017). NILAI PENDIDIKAN D ALAM AL-QUR'AN (Tafsir Q.S. Luqman Ayat 13 dan Q.S. Ash-Shaffat ayat 102-107). 127-153.

Putra, T. W. (2018). Kewajiban Mendasar Kepala Keluarga (Studi Tafsir Surat At-Tahrim: 6). 
Jurnal Ulumul Syar'i, 7(2), 65-80.

Rahmah. (2018). Pengaruh Interaksi Sosial Di Lingkungan Rumah Terhadap Perkembangan Bahasa Anak Usia 4-5 Tahun Di Paud Ayah Bunda Cililitan Jakarta Timur. Pendidikan, Jurnal Issn, Paud, 03(1), 19.

Suryani, C. (2012). Konsep Pendidikan Keluarga Dalam Surat Luqman Ayat 12-19. Jurnal Ilmiah Didaktika, 13(1). https://doi.org/10.22373/jid.v13i1.468

Thohir, U. F. (2015). KONSEP KELUARGA DALAM AL-QUR'AN ; Pendekatan Linguistik dalam Hukum Perkawinan Islam Umar. Jurnal Studi Hukum Islam, 2(1), 1-10. http://dx.doi.org/10.1016/j.cirp.2016.06.001\%0Ahttp://dx.doi.org/10.1016/j.powtec.2 016.12.055\%0Ahttps://doi.org/10.1016/j.ijfatigue.2019.02.006\%0Ahttps://doi.org/10. 1016/j.matlet.2019.04.024\%0Ahttps://doi.org/10.1016/j.matlet.2019.127252\%0Ahttp:/ /dx.doi.o

Wismanto, Y. B. (2014). DENGAN KEHARMONIS AN KELUARGA. 13(1), 84-97.

Yusmar, A. (2017). Upaya Peningkatan Teknik Permainan Bola Voli Melalui Modifikasi Permainan Siswa Kelas X Sma Negeri 2 Kampar. JURNAL PAJAR (Pendidikan Dan Pengajaran), 1(1), 143. https://doi.org/10.33578/pjr.v1i1.4381

Zubaedy, M. (2019). Konsep Pendidikan Anak Menurut Al-Quran Surat Luqman Ayat 13-19. DIDAKTIKA : Jurnal Kependidikan, 12(2), 135-150. https://doi.org/10.30863/didaktika.v12i2.182 